\title{
Analysis of Social Networking Service Data for Smart Urban Planning
}

\author{
Higinio Mora ${ }^{1, *(1)}$, Raquel Pérez-delHoyo ${ }^{2}$, José F. Paredes-Pérez ${ }^{1}$ and \\ Rafael A. Mollá-Sirvent ${ }^{1, *}$ \\ 1 Department of Computer Science Technology and Computation, University of Alicante, \\ 03690 Alicante, Spain; josefrancisco.paredes@gmail.com \\ 2 Department of Building Sciences and Urbanism, University of Alicante, 03690 Alicante, Spain; \\ perezdelhoyo@ua.es \\ * Correspondence: hmora@ua.es (H.M.); rmolla@dtic.ua.es (R.A.M.-S.); Tel.: +34-965-90-3400 (H.M.)
}

Received: 1 November 2018; Accepted: 10 December 2018; Published: 12 December 2018

\begin{abstract}
New technologies are changing the channels of communication between people, creating an interconnected society in which information flows. Social networks are a good example of the evolution of citizens' communication habits. The user-generated data that these networks collect can be analyzed to generate new useful information for developing citizen-centered smart services and policy making. The aim of this paper is to investigate the possibilities offered by social networks in the field of sport to aid city management. As the novelty of this research, a systematic method is described to know the popular areas for sport and how the management of this knowledge enables the decision-making process of urban planning. Some case studies of useful actions to make inclusive cities for sport are described and the benefits of making sustainable cities are discussed.
\end{abstract}

Keywords: Smart Cities; social networks; ambient behavioral analysis; urban planning; decision making; sustainability; accessibility

\section{Introduction}

Information and data have become a new working tools in the area of informational urbanism. From the access to information emerges the new urban paradigm that spreads to other disciplines such as cybernetics, information theory, self-organization, or systems theory, giving rise to a new urban model based on flexibility, uncertainty, and open and self-organized systems. The incorporation of these concepts into the field of urban planning is currently a process with great development potential. The traditional tools urgently need to be complemented by new tools based on information, which help to understand the increasing complexity of cities and their continuous evolution and transformation.

Thus, we are witnessing a slow reformulation of the urban planning paradigm [1,2]. The image of urban planning has gone from being static to a reality in motion, where the environment and the citizens themselves in continuous evolution are important sources of data, constantly providing relevant information for better urban planning, adapted to the real changing needs of the city, and the real requirements and preferences of citizens. To this end, the inference of information on city services usage and citizens habits is of great help to design smart urban planning actions and to improve city management [3].

The development of new Information and Communication Technologies (ICT) has led to major changes in society in recent times. Today, the proliferation of smart devices and mobile communication in the hands of users has enabled the creation of new applications and services aimed at improving the lives of citizens. This development is altering people's communication habits, their relationship with 
the environment and with others, creating an interconnected society in which information flows. ICT is affecting the growth and structure of the cities and can be used to make them more sustainable [4].

Social networks are a good example of this evolution in the citizens' communication habits. In general terms, a Social Networks Site (SNS) or Social Networking Site can be defined as a service (web-based or through a mobile App) that allow users to share a personal profile and make contacts with other users [5]. In this way, a SNS is a platform where users can spread information about themselves, their preferences, their tastes, their hobbies, their creations, or their professional activities.

The great acceptance in many sectors of society, and especially among the young population, has generated dizzying growth and ensures a promising future with many social implications. Currently, we can find the presence of social networks in many areas of society, such as social communication, education, or employment [6]. They have become a fundamental part of our lives [7]. SNS contain explicit and implicit information about social structure and almost any aspect of the daily life of citizens such as practices, preferences, pictures, etc.

The information collected into these communication spaces can be analyzed to generate new useful knowledge [8,9]. The applications of this source of data are very broad since it comes directly from users in the development of their daily activities. Thus, for example, there are previous works of analysis in the fields of education [10-12], social interaction [13], and labor [14].

Social networks are also a powerful tool to obtain knowledge about a city. Currently, they are one of the main sources of information available to urban planners in order to find out how users of the city use public space. Knowing the real uses that citizens make of urban public space is fundamental for the planning and smart design of cities.

Nowadays, governance must take advantage of new opportunities and the possibilities of the internet age [15]. New technologies enable citizens to participate in a direct way in the decision-making process. Administrations have evolved towards citizen-centric management where government and citizens can work together in designing better cities. This trend is shaping the concept of the Smart City, which is mainly characterized by the use of ICT for increasing the quality of life of its citizens [16].

This research is aimed at taking this opportunity by analyzing social network services. Specifically, this work is focused on the analysis of SNSs in the field of sport, in which users provide information related to their activity, as well as the scores, times, and routes through which they practice sport.

This work extends a preliminary approach presented at Urban Growth '18 conference [17]. In that work, the feasibility of the approach was presented through a simple analysis but no suggestions for policy-makers were proposed. Once the idea has been validated, a more detailed analysis and broader understanding of the data inferred from sporting SNS have been undertaken in this work.

In short, the main objective of this new research is to study the information retrieved from SNS on sport activities and its potential for improving urban planning of the city, that is, to design better infrastructure based on where and when it is used. As a secondary objective, this work aims to analyze the most popular areas of the coast side of the Alicante city to check its suitability for sporting activities.

The major contribution comes from the methodology used to identify the common places of the city where sport is practiced, as well as the systematic analysis performed on the retrieved data from the SNSs. Other contributions are the identification of common issues along the city and the proposals for making the urban space more inclusive, taking the City of Alicante as an example.

These contributions are also the main novelty in relation to the previous research. As will be described in the related work section, existing investigations (including our previous one) are focused on the potential of data from 'big app' companies to conduct research focused on georeferenced-point data but not specific urban actuation.

In this way, the information from sport SNSs allow implementation of policies for transforming the city into an inclusive, accessible, and usable urban space.

To address the above issues, we first conducted a review of the related work on the analysis of social network data as a source of information, and how they can be used for improving city management; next, in Section 3, we explain the possibilities offered by user-generated data retrieved 
from sport SNS; Section 4 describes an application scenario where some urban actions are proposed; and finally, conclusions and some future research lines are described in Section 5.

\section{Related Work}

The following text briefly describes the current state of knowledge on the different aspects of this research. The conclusions of related studies are also summarized below.

\subsection{New Tools for Enabling Informational Urbanism}

The emergence of new data processing technologies has provided powerful tools for informational urbanism. Big data, data mining, or data analytics are able to provide valuable knowledge about the city dynamics $[18,19]$. Recently, frameworks have been proposed to handle big-data analytics for smart city environments with advantages in comparison to traditional knowledge discovery approaches [20]. It aims to bring advanced analytics and intelligence into different domains of the city.

These techniques work in a complementary way with technologies for sensing the city. That is, to acquire the raw data about any interesting aspect to be analyzed. To this end, the Internet of Things (IoT) paradigm is revolutionizing how information can be acquired and communicated to a central server to be further processed. In this regard, researchers have studied how to develop embedded systems and devices able to read the relevant data, and how it can be transmitted over the Internet. As a result, there is a clear connection between IoT and Smart City development where government, public administrations, firms, and other stakeholders are implementing many initiatives within the city's ecosystem [21,22]. Indeed, the leveraging of new technologies and their assimilation into initiatives in the scope of informational urbanism needs to integrate different types of information and to develop capabilities for smart city managers, such as knowledge management and ICT capabilities [22].

There are many works that take advantage of the combination of big-data and the IoT for designing urban planning actions. In this line, several architectures to build all the processes involved in a smart-city project have been proposed $[23,24]$. In these architectures, the datasets are generated by the IoT layer in connection with the physical world. For example, the data can be produced by smart homes, weather stations along the city, meter sensors, surveillance objects, etc. In most of these studies, the urban planning actions are extensively preferred as they connect several regulations and have a visible effect on the life of individuals such as smart transportation, smart parking, smart travel card data, etc.

However, IoT deployment for city sensing can be very expensive and also needs additional technology infrastructure, such as base stations, gateways, Internet hotspots, etc. Instead, social networks can be also used to acquire data generated by human responses and to know their behavior. This approach will be discussed in the following subsections.

\subsection{Analysis of Social Network Sites}

Social networks have always existed among us: group of friends, families, employers of a company, etc. In some way, they are part of the human nature. However, technology and new ways of communication have enhanced this phenomenon as never before. Now, social networks are broader, more specific, and enriched with multimedia data.

The area of social network analysis is experiencing intense research activity, as evidenced by the number of recent works found. This discipline requires the contributions of different sciences (sociology, psychology, mathematics, statistics, computer science, etc.) to understand human relational phenomena and behavior, and for analyzing the data.

The analysis of SNS can be studied from two perspectives: (a) human relations and (b) the content itself being published and exchanged.

(a) From a human relations point of view, the analysis of social networks is a methodological and theoretical approach that emphasizes the study of relationships between people, organizations, countries, or things $[25,26]$. This analysis of social structures is usually made by applying graph theory 
methods [27]. These methods provide broad outcomes and indicators of a diverse nature. The outcomes are social structures that exist among interacting people, such as cohesion of groups, subgroups, predominant participants or influencers, interactions within an organization [28], etc. Discovering who does the most to connect with fellows and who is going to act as a knowledge diffuser is very helpful to focus the communication efforts [29]. These results can be of great help for many social-oriented issues, such as management improvement [30], effective marketing communications [31], or improving social media operation strategies of public administrations [32].

(b) Regarding SNS content analysis, big-data techniques have significantly enhanced the knowledge generation from social networks $[33,34]$. The main strength of this approach is the synergy between network and content to provide valuable knowledge for many purposes [35].

Currently, there is a lot of multimedia data available online through SNSs. It is basically composed of text, pictures, and videos. In most cases, this data has been posted by citizens during their daily activities. In this case, it is known as social media data. One reason for the popularity of social media is the ease of receiving, creating, and sharing information at low cost and ubiquitously [36] through the mobile devices of citizens. In this regard, democratization of smart phones among populations has highly encouraged the enormous growth of social media. Some social media networks such as Instagram, Twitter, and Facebook have become very popular with billions of users around the world. This data has increasingly interested companies in their business decision-making [37]. In this way, user's opinions on their consumer satisfaction or experience can help firms to improve their products and to offer a better service according to the characteristics, preferences, and interests of their customers.

\subsection{Analysis of Social Network Sites for Informational Urbanism}

In the area of informational urbanism, public administrations are also very interested in obtaining citizens' preferences and opinions about the city. In this way, the citizens' participation in public decision-making processes and governmental activities becomes possible because citizens can now post opinions and requirements through social networks [38].

However, the role of social networks is still an open issue for smart city purposes [39]. Big data technologies have generated new challenges in the area of analysis of social networks. These include how data can be processed and used to acquire valuable knowledge on citizens and city operation. New proposals and frameworks are appearing for analyzing SNSs in order to obtain valuable information for city managers $[40,41]$. In this line, big data analytics enables governments to build prediction models, to discover behavior patterns, and to assess citizen satisfaction [42], and also for advancing urban sustainability research and planning [43].

Some of the recent research generally aims to understand the link between people and places, and the dynamics of using the urban spaces, that is, to identify which places in the city are preferred, used, and livable $[44,45]$. There is some empirical research in relation to how the use of social networks might relate to citizens' behavior. These studies propose different methodologies to generate this information. For example, the work conducted by Martí et al. [46] aimed to identify successful public areas in the city through the location-based application "Foursquare". This is a SNS that enriches consumer experiences through a deep understanding of the location of the consumer. Other proposals are focused on discovering popular tourist attractions within the urban areas through geo-tagged images posted in Flickr [47] or Panoramio [48]. These platforms are SNSs where users can share, organize, and find multimedia content composed mainly of pictures $[49,50]$.

One of the most analysed platforms is Twitter, due to the large amount of data produced daily by messages from its users. For example, it is used to depict urban boundaries with geo-located messages [51]; to analyze the relationships between factors affecting human outdoor activity in cities, such as weather conditions and traffic congestion [52]; to enrich sensor data for environmental monitoring with those generated by citizens exploiting social network paradigm [53]; to infer coordination patters among population in a nationwide social system [54]; or to obtain socio-spatial 
relations in the city by analyzing the everyday activities of different groups. This SNS has been also used to analyze the network of different social issues, such as opinion propagation [55], urban emotions [56,57], and even human sentiments from social messages posted by users [58].

Other studies focus on how the visualization of social network data can be used to explore the relationship between citizens' movements and activity distributions. For example, the work by Zeng et al. [59] identifies some points of interest throughout the city where a high density occurs; and the research conducted by $\mathrm{Wu}$ et al. [60] proposed a graphical representation to characterize the spatial and temporal mobility of the citizens.

In the case of social networks for sport, there are recent initiatives that study how this data can be exploited to make better cities [34,61-63]. These analyses are mainly focused on taking advantage of the available georeferenced-data taken by the citizens' GPS devices during their sport activity and voluntarily uploaded to SNSs. These works are focused on cycling activity but not on pedestrian sports. The outcomes include some information of interest about the use of the city's infrastructure, such as origin and destination areas of the city, popular or avoided routes, or intersection wait times.

However, much remains to be done. Firstly, to transform this information into useful knowledge that improves urban planning processes; and secondly, to provide urban planners with new planning tools.

On the one hand, from the continuous interaction with the environment and the users of the city, a new understanding of urban capacities and opportunities emerges that makes a new urbanism possible that is more human and flexible, where the citizen is a participant and not a mere observer [64]. On the other hand, it is in this context of the new urban model based on the paradigm of smart cities where it is necessary to reformulate the paradigm of urban planning, which necessarily involves considering people at the centre of planning and which requires new tools to be put into effect $[65,66]$.

Therefore, the latest ICTs and SNSs have transformed the traditional meaning of citizen participation. This new understanding of citizen participation has important implications for the planning and design of cities of the future. City planning has gone from being the responsibility of planners to representing a collective challenge which involves both governments and citizens $[67,68]$.

\subsection{Findings}

After reviewing the main related works, we can draw the following issues that justify and summarize our contributions in this field:

1. Informational urbanism needs to be fed by valuable knowledge to be useful for designing smart urban planning actions. Big data technology and the IoT play a vital role in providing it, but they need to integrate different data sources and have deployment costs.

2. The analysis of SNSs is a growing research discipline that has important implications in many areas of society. This analysis can be done from a human relation point of view, or from a content perspective. As a result, valuable information of the preferences, habits, and behaviors of citizens can be obtained.

3. Using data from SNSs opens new possibilities to identify the real uses of urban spaces. This information contributes to the construction of the informational urbanism concept and opens new management possibilities to perform urban planning actions taking into account the dynamics of the city.

Based on the above, this work identifies two research gaps: first, to find out if valuable knowledge for pedestrian urban planning can be also obtained from data of SNSs, and secondly, how these data can be used to derive urban actions to integrate sport within the city.

The work described in this paper addresses the abovementioned two points by developing a method for analyzing the data from SNSs for sport. It aims to demonstrate the value added by knowledge generated by these SNSs which enables the design of citizen-centric policies for smart urban planning. In addition to the results of other works in this area, the step forward of this research 
lies in proposing specific urban planning actions as an example of the progress in making more inclusive cities.

\section{Analysis of Social Networking Services for Sport}

Recently, the news headlines have informed people that American soldiers and their secret bases around the world were revealed due to a sport application [69]. The owner of this App has published a heat map with all its users' activities, including military who use this 'App' for sport and training [70]. The map also shows the intensity of the movements. It is, according to its designers of the 'App', "a live view of worldwide network of athletes.

New Social Media are the communication channel of the new generations, especially those who use the internet as a source of information [71]. Among the many SNSs for sport, this work has explored a variety of sites with the aim of learning about their diversity and the variability of the information available. Table 1 describes some of most common SNSs for sport.

Table 1. Social Networks Sites for Sport Activities.

\begin{tabular}{|c|c|}
\hline Social Network & Web Site \\
\hline & $\begin{array}{c}\text { http:/ / www.atletosports.com/ } \\
\text { This is a is a sports social network to connects athletes } \\
\text { with each other to facilitate games or other } \\
\text { athletic activities }\end{array}$ \\
\hline & $\begin{array}{l}\text { https: / / www.strava.com/ } \\
\text { Social network to share activities with a broad social } \\
\text { community of registered users }\end{array}$ \\
\hline & $\begin{array}{l}\text { http: / / www.mapmyrun.com/ } \\
\text { Social network to share the sports activity linked to } \\
\text { the sports products company Under Armor }\end{array}$ \\
\hline & $\begin{array}{c}\text { https: / / www.runtastic.com/ } \\
\text { Social network to track and manage health and } \\
\text { fitness data }\end{array}$ \\
\hline & $\begin{array}{l}\text { https://runkeeper.com/ } \\
\text { It is a top social network that helps people get out the } \\
\text { door and stick with running. }\end{array}$ \\
\hline & $\begin{array}{l}\text { https: / / www.sports-tracker.com/ } \\
\text { Social network where sports enthusiasts can access to } \\
\text { public workouts, every day }\end{array}$ \\
\hline & $\begin{array}{c}\text { https: / /www.gotzam.com/ } \\
\text { Social network to share sport events and activities } \\
\text { among users }\end{array}$ \\
\hline
\end{tabular}

On these platforms, users provide information on the development of their activity and they post data on scores, times, and routes where they do their sport. Data on these aspects are introduced by users themselves on a voluntary basis with the aim of sharing their experiences and comparing their marks with other users.

The process of data generation and communication to the SNS is usually done automatically through the users' mobile devices, such as smart watches, phones, and other wearable devices with Global Positioning System (GPS) functionality. After that, the route of the sport activity made by the user can be drawn easily on a map.

\subsection{Data Visualization}

All the sites analyzed provide information on the routes followed by users in the practice of their sport for each city where the social network is used. These routes can be viewed directly through a 
web-based interface for a desktop browser or through a mobile device application for a smartwatch or smartphone. The interfaces of these applications are very useful and intuitive, and include searching tools to find the sport activity, for example, time duration, length, type of sport, city, region or country, etc. Furthermore, they usually provide the best marks and the users that have followed each race. In addition, they offer premium services for registered users that include additional features such as the creation of training plans, advanced sports performance statistics, health guides, and access to personal trainers.

Figure 1 shows an example of the interface centered on the city of Alicante (Spain) of one of the most popular SNSs studied.

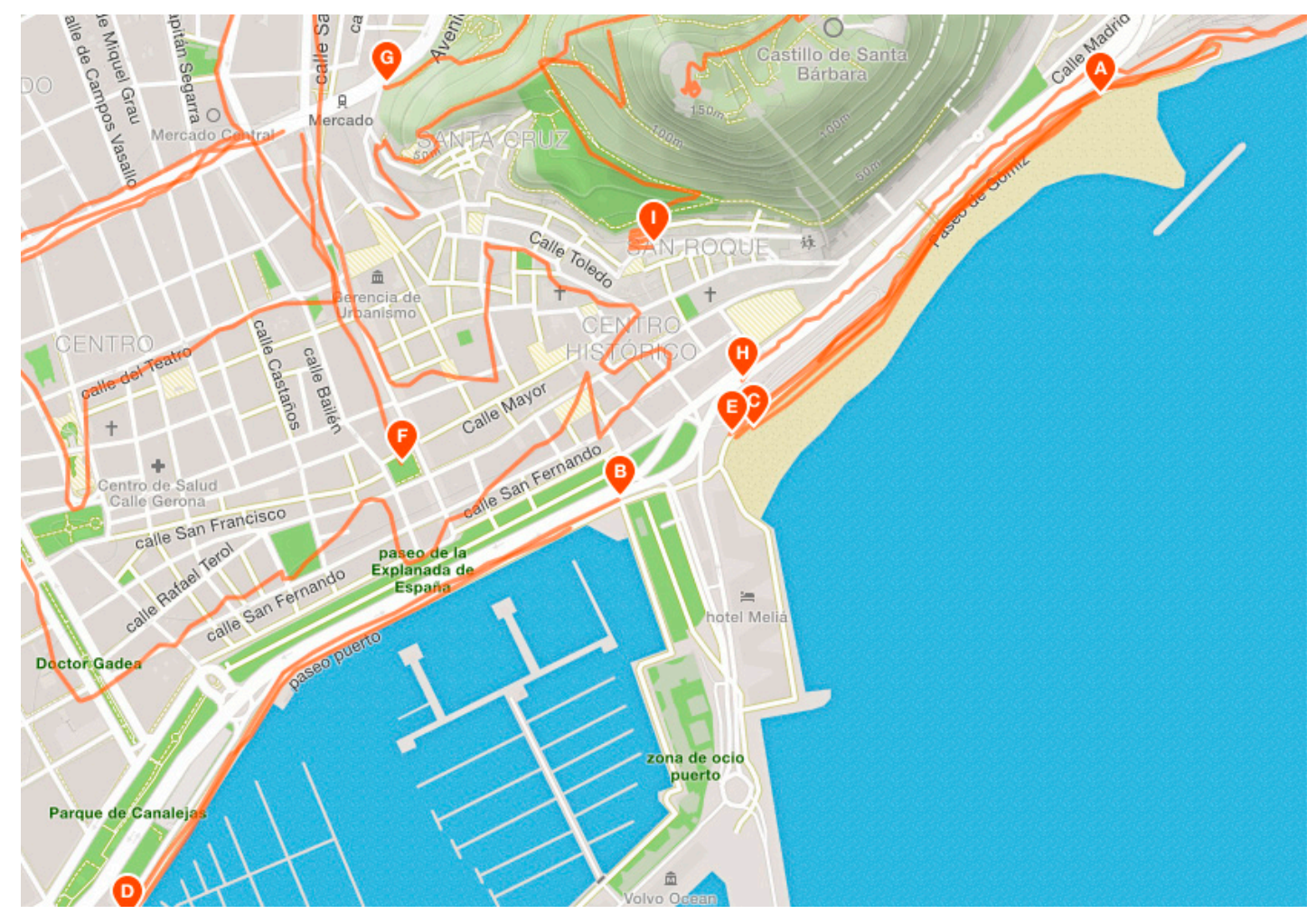

Figure 1. Example of the interface centered on the city of Alicante. Retrieved from the Strava social network on 28 October 2018. Orange lines represent the routes uploaded by users. Each marker has a number with the route identifier in the application.

A set of routes drawn on the map can be observed in Figure 1. Each of these routes has been covered by at least one user. For each of them, a lot of information can be obtained. This detail includes, for example, distance travelled, time spent, average slope, and estimated calories burned. Figure 2 shows the details of a route provided by one of the most popular social networks. As shown, this example route has been run by 3973 citizens doing sports in the city. Using the search tools of the SNS studied, it is possible to identify the existing routes in a city or geographical area.

In addition, the data can be filtered by dates in order to retrieve information on when and where the sport practice is done. Thus, valuable information for urban planning can be obtained from the knowledge on where and when each sport is actually performed by citizens.

Apart from the web platforms of these SNSs, Geographic Information Systems can be used for applying advanced visualization techniques and further analysis. 

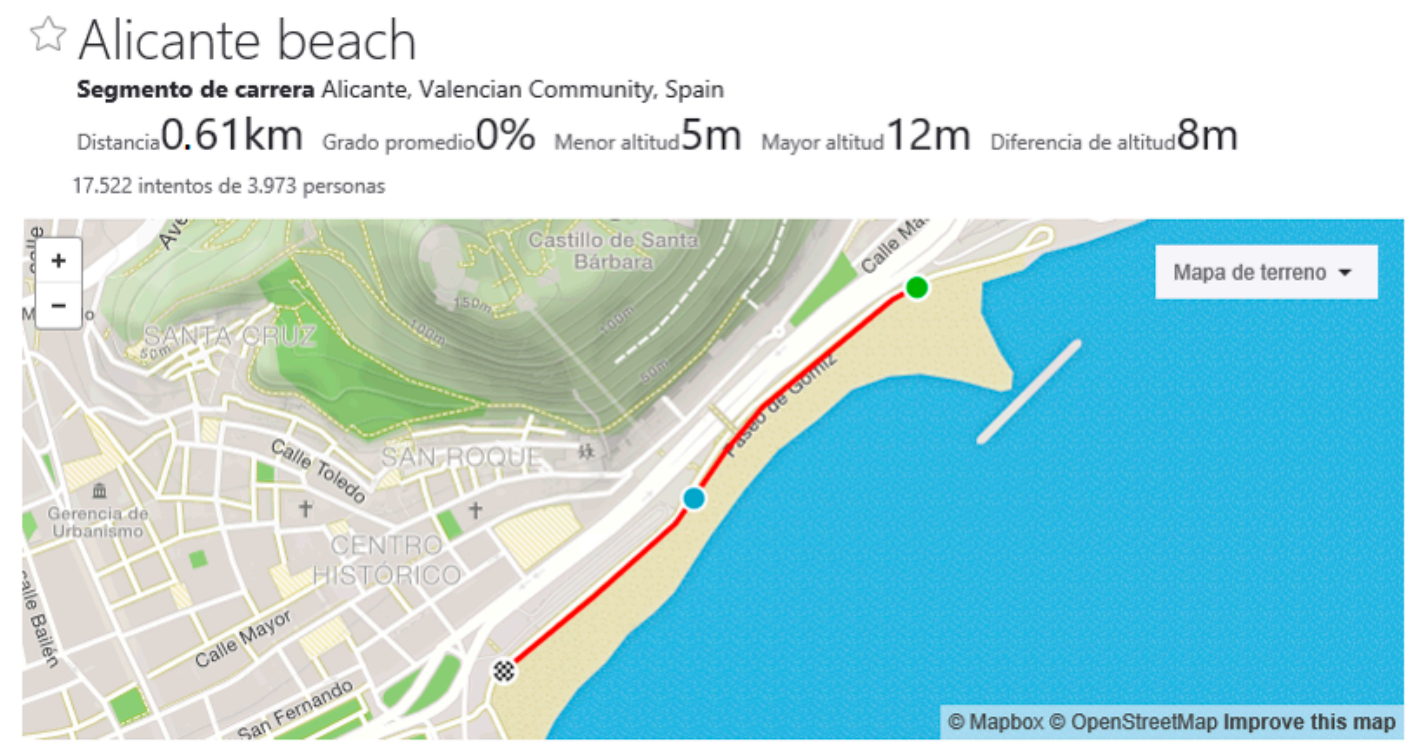

Figure 2. Route details of the "Alicante beach" route. Data retrieved from the Strava social network on 28 October 2018. Markers show the origin, middle, and destination points of the route.

\subsection{Data Download}

The routes stored in the sport SNSs are generated by the users thought their mobile devices or wearables when they are practicing sport. Usually, these devices are equipped with a GPS device which tracks the sport activity. Once the sport activity has finished, the mobile devices or wearables upload the activity features to the SNSs by themselves. Millions of GPS-tracked activities are uploaded to these platforms every week [34].

These routes can be easily downloaded from the platform for analysis. There are several commonly used structured geopositioning formats in which the routes can be codified for further processing. These formats are generally based on the XML schema. Table 2 lists the most common geopositioning formats.

Table 2. Common geopositioning formats

\begin{tabular}{|c|c|}
\hline Format & Description \\
\hline $\begin{array}{c}\text { KML } \\
\text { (Keyhole Markup Language) }\end{array}$ & $\begin{array}{l}\text { Designed by Google for representing geographic data in } \\
\text { three dimensions. It is used by Google Earth } \\
\text { (https://developers.google.com } / \mathrm{kml} / \text { schema } / \mathrm{kml} 21 . x s d \text { ) }\end{array}$ \\
\hline $\begin{array}{c}\text { GPX } \\
\text { (GPS eXchange Format) }\end{array}$ & $\begin{array}{l}\text { It is an open standard for the interchange of GPS data } \\
\text { between applications and Web services } \\
\text { (https: / / www.topografix.com/GPX/1/1/gpx.xsd) }\end{array}$ \\
\hline $\begin{array}{c}\text { TCX } \\
\text { (Training Center XML) }\end{array}$ & $\begin{array}{c}\text { Designed by Garmin and used to track an sport activity with } \\
\text { a mobile device (https:/ / www8.garmin.com/xmlschemas / } \\
\text { TrainingCenterDatabasev2.xsd) }\end{array}$ \\
\hline $\begin{array}{c}\text { GTM } \\
\text { (GPS TrackMaker) }\end{array}$ & $\begin{array}{c}\text { Designed by TrackMaker for creating routes and detailed } \\
\text { maps from GPS information } \\
\text { (https://www.trackmaker.com/) }\end{array}$ \\
\hline GeoJSON & $\begin{array}{l}\text { Open format based on JavaScript Object Notation (JSON) for } \\
\text { encoding a variety of geographic data structures } \\
\text { (https:/ / tools.ietf.org } / \text { html/rfc7946) }\end{array}$ \\
\hline $\begin{array}{c}\text { GML } \\
\text { (Geography Markup Language) }\end{array}$ & $\begin{array}{l}\text { Designed by Open Geospatial Consortium for representing } \\
\text { geographic information } \\
\text { (http:/ / www.opengeospatial.org/standards/gml) }\end{array}$ \\
\hline
\end{tabular}


As an example of content structure, Figure 3 illustrates the path shown in Figure 2 both in KML and GPX formats. As shown in Figure 3, these file formats represent each route by means of the set of individual points that compose it. Each point is a special location defined by a single geodetic longitude, geodetic latitude, and (optional) altitude coordinate tuple. Other information such as the device used to register the route is stored. The proliferation of wearables and smart watches has definitely contributed to promoting the social interaction of athletes.

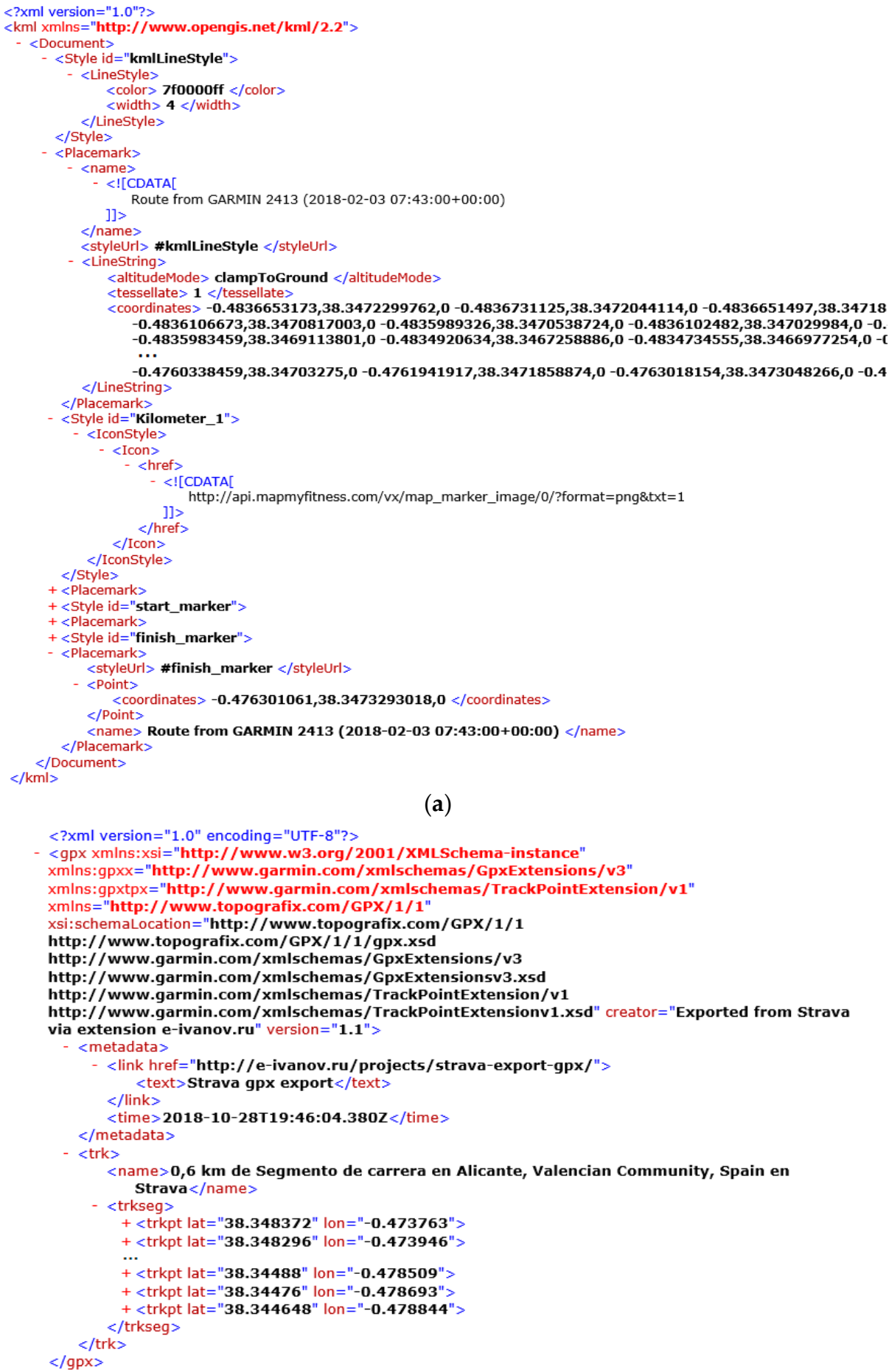

$<$ ?xml version="1.0" encoding="UTF-8"?>

<gpx xmlns:xsi="http://www.w3.org/2001/XMLSchema-instance"

xmlns:gpxx="http://www.garmin.com/xmlschemas/GpxExtensions/v3"

xmlns:gpxtpx="http://www.garmin.com/xmlschemas/TrackPointExtension/v1"

xmlns="http://www.topografix.com/GPX/1/1"

xsi:schemaLocation="http://www.topografix.com/GPX/1/1

http://www.topografix.com/GPX/1/1/gpx.xsd

htt:///www.garmin.com/xmlschemas/GpxExtensions/v3

http://www.garmin.com/xmlschemas/GpxExtensionsv3.xs

http://www.garmin.com/xmlschemas/GpxExtensionsv3.xsd

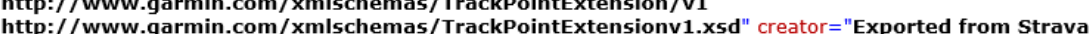
via:/

Figure 3. "Alicante beach" route file example. (a) KML format; (b) GPX format. 
In order to obtain useful information in an effective way, it is necessary to perform an automated analysis of a route's information. The use of massive analysis techniques is required to download the routes and process them. The social networks studied provide computer tools that allow applications based on the information they contain to be developed. To this end, they have a specific Application Programming Interface (API) to access the services they offer, such as: Strava (https://developers.strava.com/); Mapmyrun (https://developer.underarmour.com/), and Runtastic (https://github.com/runtastic). The first two tools also offer a RESTful web service delivery architecture with structured data exchange communication in JavaScript Object Notation (JSON).

The social network Strava provides a service for data aggregation oriented to departments of transportation and city planning groups (https://metro.strava.com/). In order to maintain the privacy of users, data downloaded from SNS are anonymized by removing all personal data of each route. Among the operations they provide is the query of available route sets according to established search criteria, including the geolocation of the area of interest and the radius of action. In this way, collections of routes can be obtained for mass analysis of any given city.

The analysis of this information makes it possible to determine the date, recording time, and the places in the city where each activity has been carried out. This provides accurate information on citizens' actual sports habits and their evolution over time, and therefore is a useful tool for knowledge generation about the real uses of urban spaces.

\section{Smart Urban Planning}

New free ways of using public space are constantly emerging in cities at the initiative of citizens without having been previously thought or planned. These are new uses or new ways of understanding public space that are quickly disseminated and shared among the users of a city and among different cities. A good representative example of the current situation is the use of urban public space for sports-related activities. Increasingly, citizens share information on social networks about new routes or places where, due to their appropriate characteristics, they choose to carry out their daily sporting activity. It is evident that this information on the use that citizens make of public space, on their needs and preferences, understanding the fact of voluntarily sharing this information in SNSs as a current form of public participation in the organization of the city, cannot be left out of the decision-making process about the right urban planning actions to design smart today's cities.

The research question can be defined in general terms as how these technological advances make it possible to incorporate this information into the planning process to recognize the capacity and right of citizens to make decisions about the city. In this sense, the management of this knowledge aids the decision-making processes of urban planning.

In this work, we have focused on studying routes of citizens that only include pedestrian sport activities such as walking, hiking, and running. Other sports practiced in city environments, such as cycling or skating, can also be analyzed in the same way.

\subsection{Methodology}

In this section, a case study is conducted for the city of Alicante. Alicante is a Spanish city of medium size (coordinates: $38^{\circ} 20^{\prime} 43^{\prime \prime} \mathrm{N} 0^{\circ} 28^{\prime} 59^{\prime \prime} \mathrm{W}$; area: $201.27 \mathrm{~km}^{2}$; population: 328,648 ) located at the east of the country on the Mediterranean coast. This application scenario has good potential for analysis since this is a very touristic place, visited by around 2.2 million tourists per year [72].

The methodology used for this scenario is empirical, and it is based on the results of some case studies. A methodology based on analysis of case studies can be appropriate when researching "how" or "why" questions about contemporary phenomena over which the investigator has little or no control $[73,74]$. This is especially suitable for studies in real-life contexts where this type of analysis can provide better understanding of the context where the study is developed, including city and regional planning research [74]. From the case study strategy, new hypotheses and research questions can arise from the results. 
The case studies described in this work are not the full set of issues and proposals, indeed, we have found some other issues in the city regarding where and when usually citizens do sport. Nevertheless, we have carried out an information-oriented selection of the study cases [75]. We look for paradigmatic cases for our context, that is, we have carefully chosen the study cases to be representative of what may be found throughout the city, and to consider them as illustrative examples of the decisions and urban planning actions that can be carried out for addressing them.

The method for obtaining the common places of the city where sport is practiced is described by the following steps:

In first place, the city area is selected. To this end, the web-based interfaces of the SNSs are visited to observe the aggregated data and visualize spatial distributions of routes. This information allows one to know at first glance the sport habits, atypical locations, or frequent places and streets where sport is practiced. From this observation, the interest area of the city is selected for route downloading. In this research, we have mainly focused on the coast side of the city, where the seafront promenade and the beach are, because these are very touristic places. This is a little part of the city, but it is a representative sample of the results of the analysis. For this area, we have retrieved the routes from the three most used SNSs: Strava, Mapmyrun, and Runtastic. As mentioned in the previous section, the routes are codified in structured data formats such as those depicted in Figure 3.

Secondly, the places of the city under study are characterized. That is, the geo-codification of each place, such as the street, square, promenade, or road of the city. This codification consists of representing these places by a polygon with georeferenced vertices. The places can be defined totally or partially according to the required precision. For example, a long street can be divided into several pieces.

Finally, identification of the places through which the sport routes pass is conducted. This procedure is made by comparing each route point-by-point with the characterized places of the previous step.

For example, Figure 4 shows an overview of this procedure for a square of the city. This comparison can extract the places where routes pass.

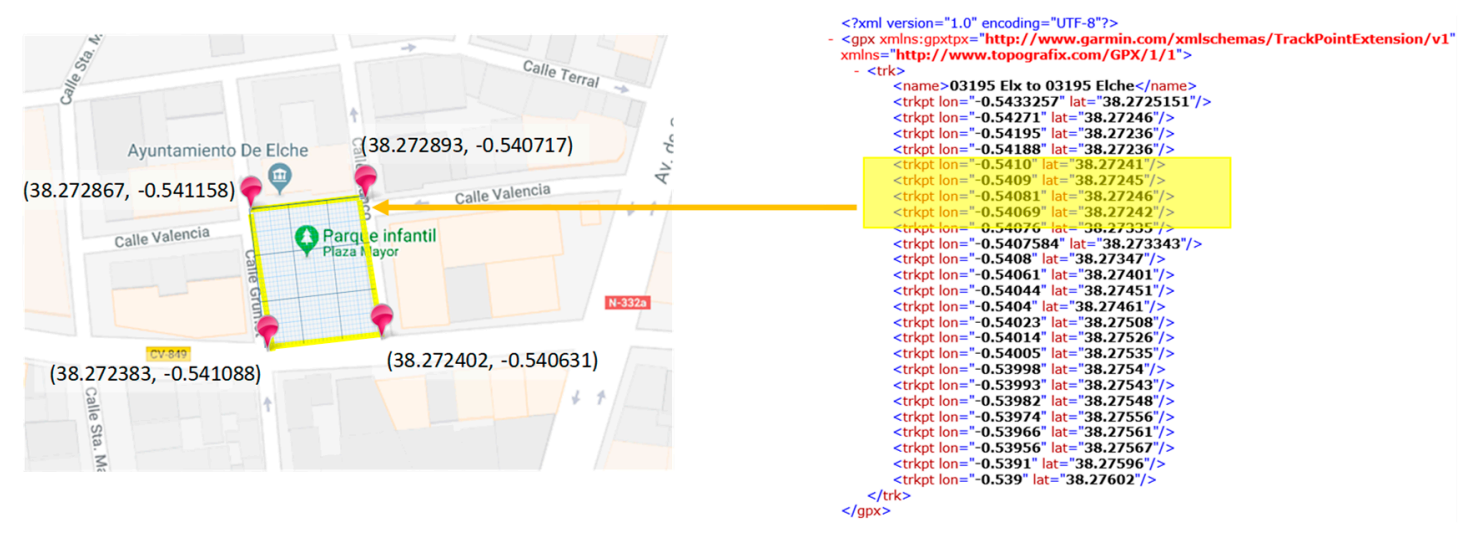

Figure 4. Example of identification of places through which each route passes.

The list of the common places frequented by citizens when they practice sport is generated as a result of the comparison process on a set of selected routes. Figure 5 illustrates this process for an example route.

Having information about which places are preferred and used by citizens to practice sport in the city is an essential tool for city managers. In this sense, the analysis of the routes stored in the SNSs allows us to identify the urban areas and infrastructures where the users' sports activities are practiced. 


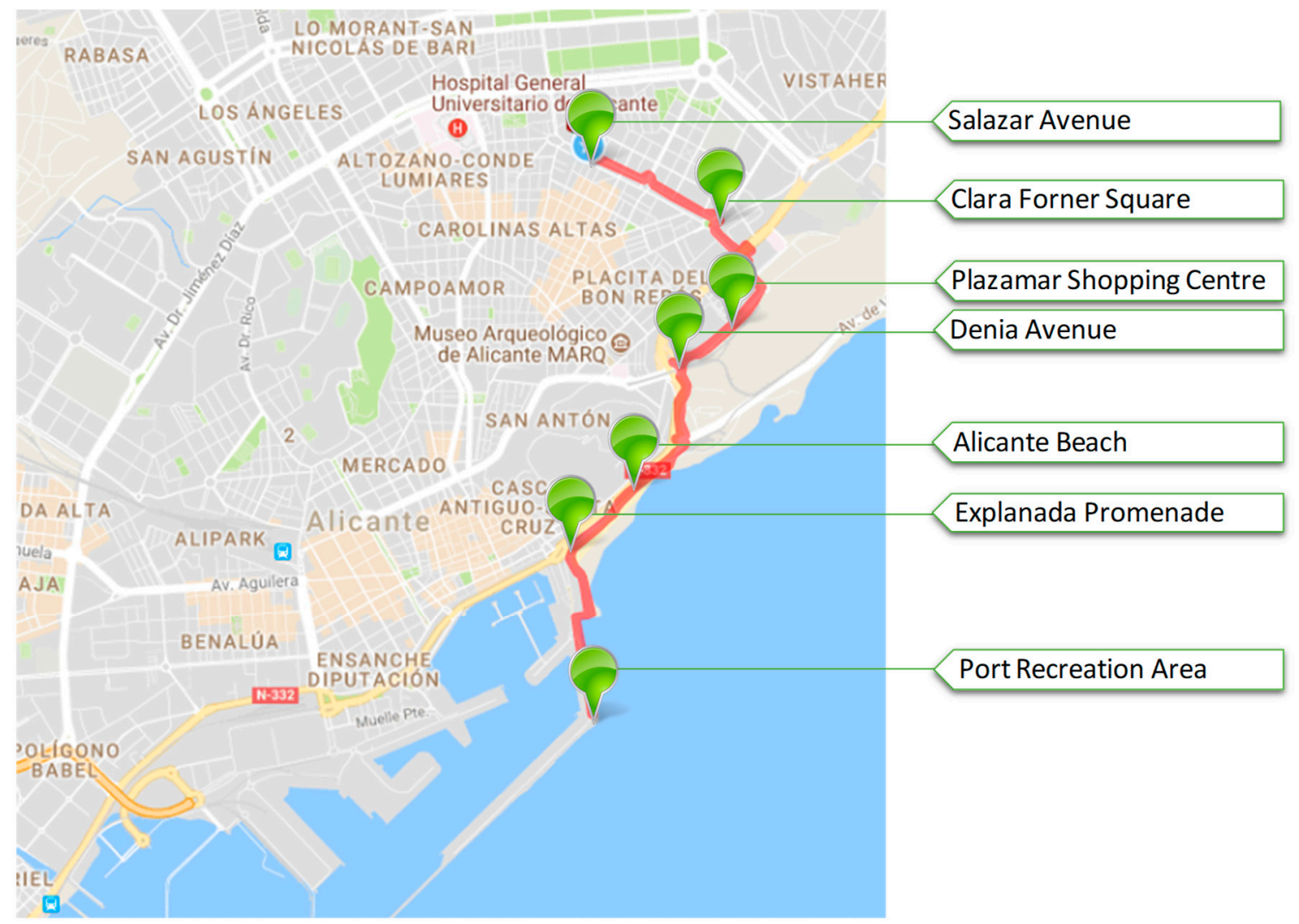

Figure 5. Route example matching. Data retrieved from the Mapmyrun social network on 30 October 2018. Markers represent the identified points along the route. Each of them corresponds to a known place of the city.

\subsection{Analysis and Proposals}

The generation of knowledge about the city is the result of this analysis step. The analytical technique used consists of building an explanation of each case [74]. That is, to describe the issues from an urban planning point of view that cause unsuitable conditions for doing pedestrian sport and potential actions to solve them. In this sense, this analysis is mainly explanatory.

As mentioned, the search through the web interface of the SNSs provides us with the map of where the routes occur. Figure 6 illustrates several routes for the common transit areas observed. A detailed search shows that these are popular places for running in Alicante. Figure 7 shows the high density of routes found in these areas.

It seems that it is more fun to run around the city than in sport centers, and after a preliminary analysis, the coast side of the city is one of the more popular areas. This preference creates the challenge to make inclusive cities where the sport activities can be part of daily city life. That is, runners can be integrated with pedestrians. A priori, this seems difficult when there are many crossroads or people on the streets. However, addressing this challenge could encourage more people to do sport and to make a better use of public spaces.

Some ideas based on the following examples can be proposed for decision-making processes of urban planning to make more inclusive and accessible cities for sport. The study cases have been illustrated with pictures from Google Maps and Street View applications. For the areas of the city under study, and based on the effective routes acquired from social networks, the following issues and proposals for addressing them are pointed out:

(i) Address the unexpected consequences in the operation of urban environments. There are many inefficiencies in the operation of urban infrastructure that make it difficult to do sport and lower the city's accessibility in general [76]. For example, the installation of public furniture, street lamps or 
traffic lights in the sidewalks. In the analyzed area there are many obstacles of this kind. For example, in Figure 8, besides the palm trees, there are many bins and lamps in the middle of the sidewalk. These obstacles might be removed or shifted to one side. In addition, some other actions, such as making broader sidewalks, should be studied, even if it means reducing the space for vehicles.
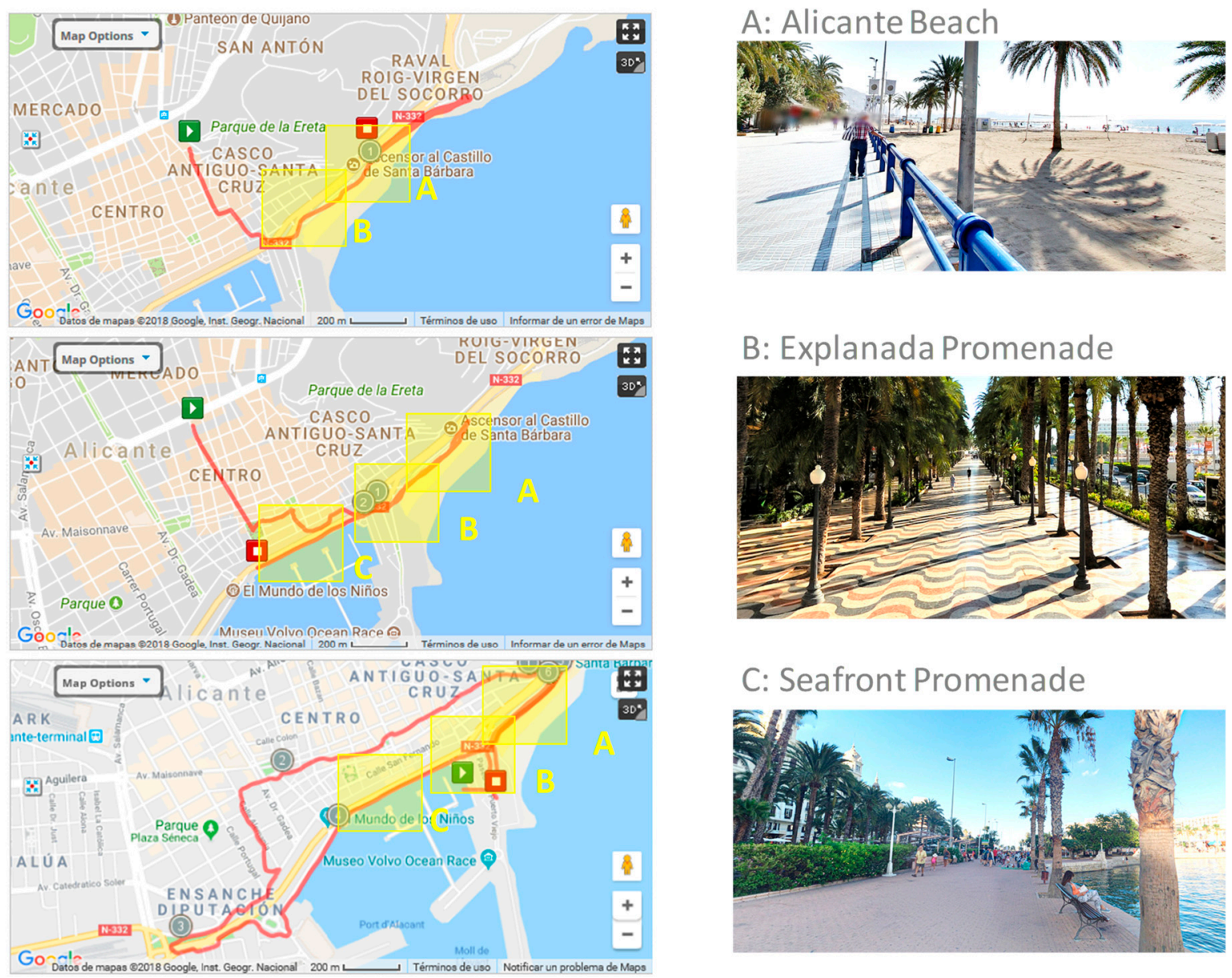

\section{C: Seafront Promenade}

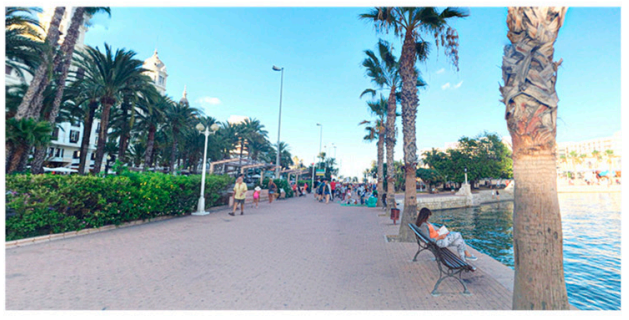

Figure 6. Common routes across Alicante city. Data retrieved from Mapmyrun social network on 26 October 2018. Red lines represent the routes uploaded by users. The tagged yellow areas (A-C) in the maps correspond to the photographed places through which the route passes.

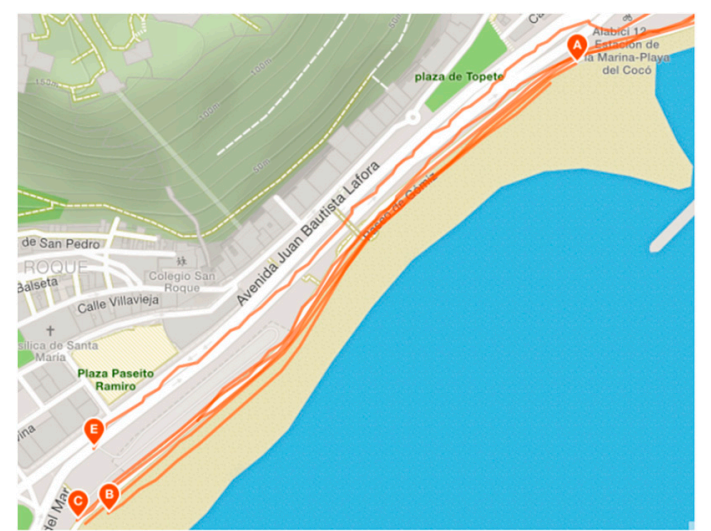

(a)

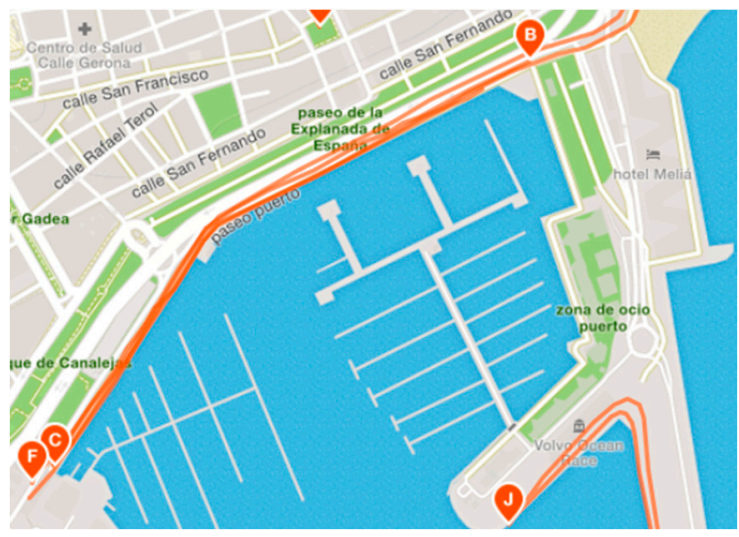

(b)

Figure 7. Density of routes. (a) Alicante Beach; (b) Explanada and Seafront promenade. Data retrieved from the Strava social network on 30 October 2018. Orange lines represent the routes uploaded by users. 

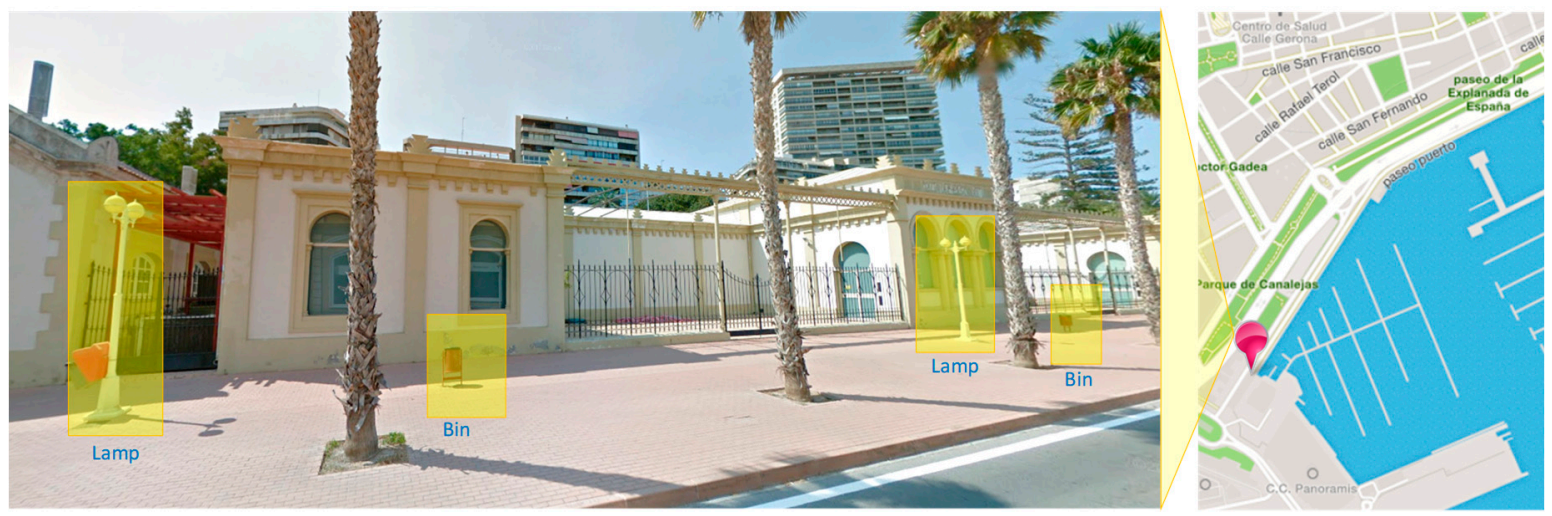

Figure 8. Alicante urban planning examples. (i) Unexpected consequences. Pink marker indicates the place in the map that corresponds with the picture on the left.

(ii) One issue for runners is having to stop at traffic lights or crossroads frequently. Therefore, city intersections could be minimized where urban sport is practiced. For example, by designing overpasses and underpasses to the road. Within the area analyzed, there are two conflictive crossroads, for both runners and pedestrians. Figure 9a shows a widely used crossroad between 'Explanada' and Seafront promenade where it could be beneficial to consider an overpass. Indeed, this solution has been already implemented $558 \mathrm{~m}$ further along in the same road (Figure 9b).

(b)

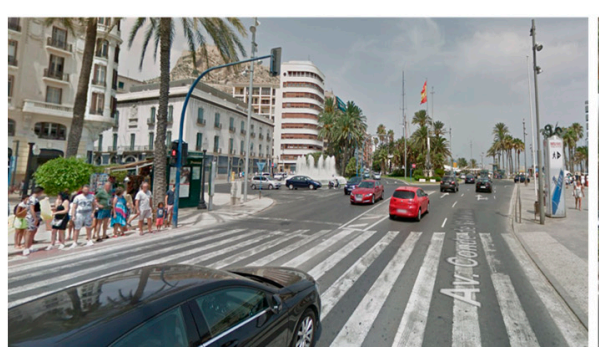

(a)

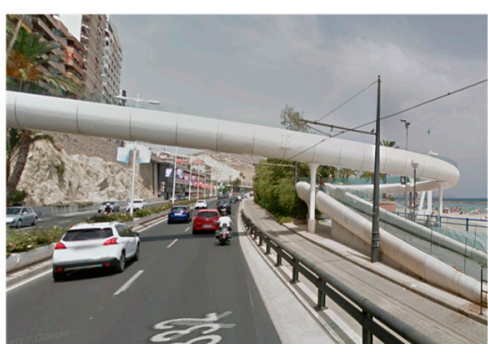

(b)

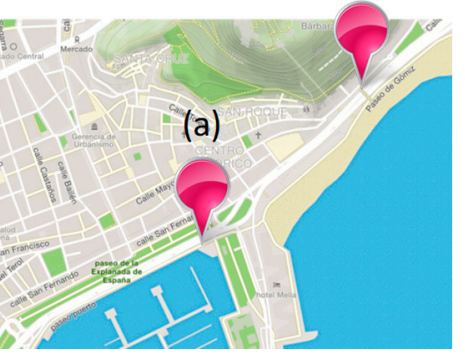

(a)

Figure 9. Alicante urban planning examples. (ii) City intersections: (a) populated crossroad; (b) existing infrastructure. Pink markers indicate the places in the map that correspond with the pictures on the left.

(iii) Special lanes could be waymarked to delimit the space for runners, similar to what is done for cyclists. In addition, other marks could be included, such as distance indicators or alternative paths. Figure 10 shows an example that could be implemented to this end. These special lanes could be available for sport for only some hours a day, according to the habits of runners or avoiding the times with the most pedestrians. In this case, the social networks provide useful information to make decisions on this issue.

Two major lifestyle components are physical activity and nutrition [77]. Moreover, the connection between doing sport and living a healthy lifestyle is unquestionable. In this sense, some of the behavioral indicators used for measuring the quality of life of the city include participation in sports and the amount of walking and bicycling activities in the city [78].

Traditionally, city managers build sports facilities in the city (sport centres, running tracks, etc.) to promote sport and healthy lifestyles. However, transportation for exercise is becoming less common, especially among young people [79]. New habits of urban life suggest that many citizens do sport within the city using the standard infrastructure. Knowledge generated from sport social networks not only verifies this trend, it also provides information of when and where sport is practiced. Hence, carrying out urban planning actions for making inclusive sport activities in the city could increase the quality of life of citizens, and enhance their interest in sustainable forms of movement in the city. 

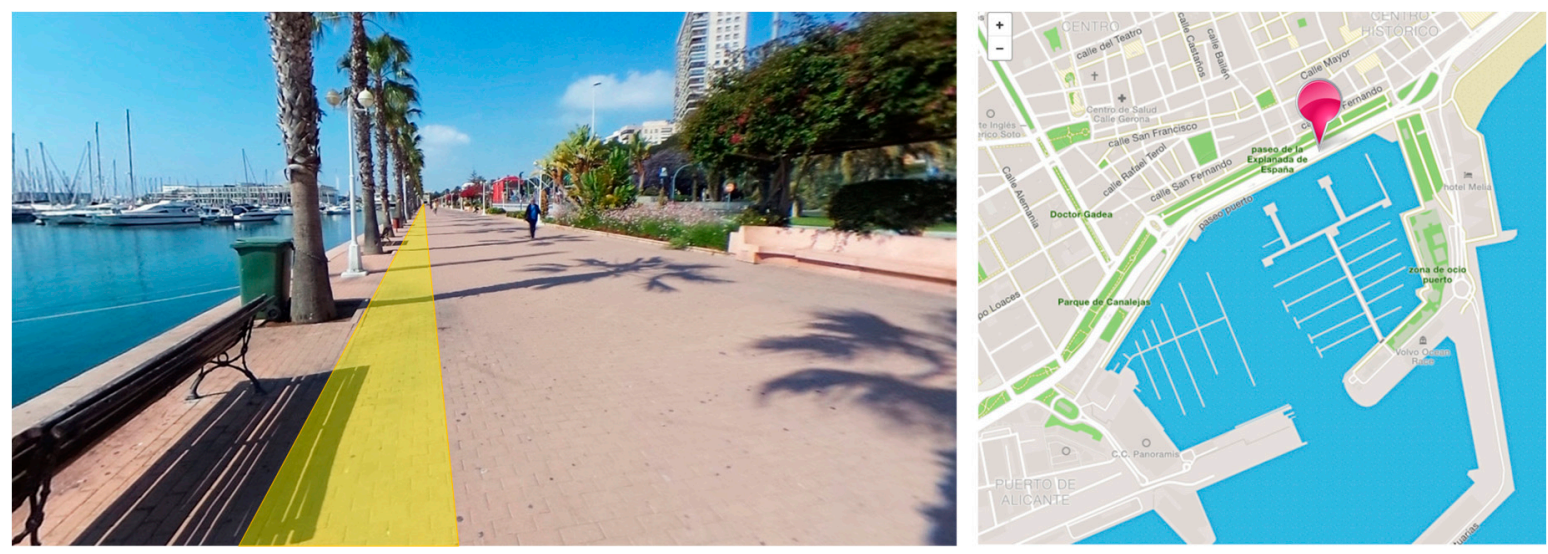

Figure 10. Alicante urban planning examples. (iii) Space for runners. Pink marker indicates the place on the map that corresponds with the picture on the left.

In addition, making suitable infrastructure for sport provides other kinds of social benefit for the city. Social interactions are enhanced by sporting activities. In this way, urban spaces become a new method for creating possibilities of interaction among citizens [80].

Another issue is the management of this knowledge, since social networks are dynamic systems. This feature could also enable agile urban planning and policy-making.

\section{Conclusions}

Doing outdoor physical activity around cities is a new trend of urban citizens. There are many synergies between physical activity and health. Policy makers and urban planners should take this into account in order to promote sport activities and make more inclusive and sustainable cities.

A set of measures consists of adapting city infrastructure to the citizens' needs. To this end, there are new ICT tools able to aid in urban decision-making. These tools are part of the knowledge-related infrastructure block of the conceptual framework of informational urbanism [16]. In this way, social networks for sport provide useful information about how city infrastructure is used, what actions are required, and where they are needed. Through all these networks, valuable knowledge can be obtained by applying simple techniques to the data voluntarily generated by users.

In this work the most relevant SNSs for sport have been studied in order to assess the suitability of urban infrastructure for pedestrian sport activities. By analyzing the data from SNSs, we can infer the popular areas of the city for doing sport. As a result, we have found that sport is practiced more within the city than in sport-dedicated infrastructure, such as sport centers, athletics tracks, or sports halls.

This knowledge is very important to improve the urban planning and design process of the city. In response to the questions raised in this work, we have identified some typical issues along the popular areas of the Alicante city where citizens frequently do pedestrian sport. Taking them as case studies, a proposal has been done for each of them in order to make the city more inclusive and to promote sport among the population.

The limitations of this study are common to other analyses of human preferences using data from social networks, that is, the representativeness of the sample. Not all citizens who do sport in the city are users of these SNSs. Nevertheless, these SNSs have a growing number of users and cover heterogeneous areas around the world. In addition, the described cases are not exhaustive, but they may be regarded as typical samples of how the information from SNSs can be used for improving the urban planning process for citizens. In this regard, the findings could rely too much on specific phenomena.

In the future, we plan to extend this study to the entire city of Alicante in order to further characterize sport-related issues. To this end, we will conduct a large-scale analysis of the urban physical activities stored in the Strava Metro information system. In addition, we plan to enhance the 
inference of the citizens' needs and urban requirements by applying advanced big-data techniques to the information processing.

Author Contributions: All authors were involved in the foundation items. All authors wrote the paper and read and approved the final manuscript.

Funding: This work has been funded by the Conselleria de Transparència, Responsabilitat Social, Participació

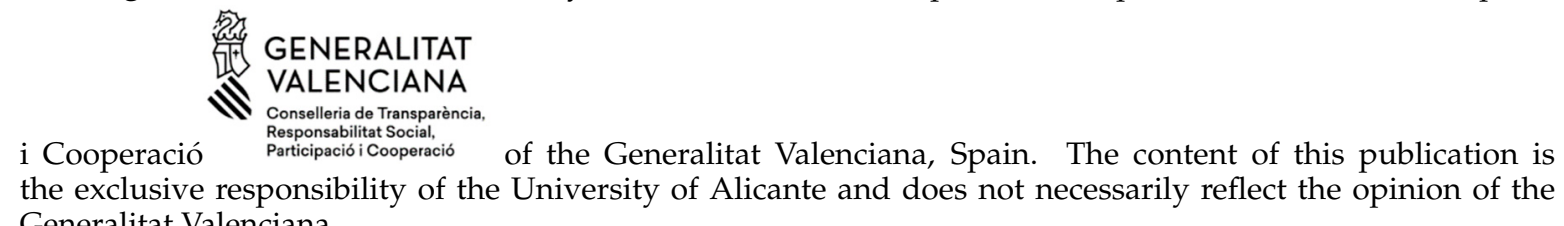
the exclusive responsibility of the University of Alicante and does not necessarily reflect the opinion of the Generalitat Valenciana.

Conflicts of Interest: The authors declare no conflict of interest.

\section{References}

1. Marsal-Llacuna, M.-L.; Fabregat-Gesa, R. Modeling citizens' urban time-use using adaptive hypermedia surveys to obtain an urban planning, citizen-centric, methodological reinvention. Time Soc. 2016, 25, 272-294. [CrossRef]

2. Mueller, J.; Lu, H.; Chirkin, A.; Klein, B.; Schmitt, G. Citizen Design Science: A strategy for crowd-creative urban design. Cities 2018, 72, 181-188. [CrossRef]

3. Mora, H.; Gilart-Iglesias, V.; Hoyo, R.P.-D.; Andújar-Montoya, M.D. A Comprehensive System for Monitoring Urban Accessibility in Smart Cities. Sensors 2017, 17, 1834. [CrossRef] [PubMed]

4. Gossling, S. ICT and transport behaviour: A conceptual review. Int. J. Sustain. Transp. 2018, 12, 153-164. [CrossRef]

5. Boyd, D.M.; Ellison, N.B. Social Network Sites: Definition, History, and Scholarship. J. Comput. Med. Commun. 2007, 13, 210-230. [CrossRef]

6. Suciu, B.F.; Albu, S.I.; Stefan, V.; Suciu, S.; Halunga, O.A.; Mohamad, R.T.; Hameed, C.; Butca, G. Monitoring of social networking sites. In Proceedings of the 2015 14th RoEduNet International-Networking in Education and Research (RoEduNet NER), Craiova, Romania, 24-26 September 2015; pp. 214-217. [CrossRef]

7. Persia, F.; D'Auria, D. A Survey of Online Social Networks: Challenges and Opportunities. In Proceedings of the 2017 IEEE International Conference on Information Reuse and Integration (IRI), San Diego, CA, USA, 4-6 August 2017; pp. 614-620. [CrossRef]

8. Garcia-Cuerva, A.; Ledezma, A.; Sanchis, A.; Iglesias, J.A. Social network analysis: Evolving Twitter mining. In Proceedings of the 2016 IEEE International Conference on Systems, Man, and Cybernetics (SMC), Budapest, Hungary, 9-12 October 2016; pp. 1809-1814. [CrossRef]

9. Akhtar, N. Social Network Analysis Tools. In Proceedings of the 2014 Fourth International Conference on Communication Systems and Network Technologies, Bhopal, India, 7-9 April 2014; pp. 388-392. [CrossRef]

10. Mora, H.M.; Pont, M.T.S.; Casado, G.D.M.; Iglesias, V.G. Management of social networks in the educational process. Comput. Hum. Behav. 2015, 51, 890-895. [CrossRef]

11. Bekele, T.M.; Wang, W.; Xia, F.; Liu, H. Big Scholarly Data: A Survey. IEEE Trans. Big Data 2017, 3, 18-35. [CrossRef]

12. Mora, H.; Ferrández, A.; Gil, D.; Peral, J. A Computational Method for Enabling Teaching-Learning Process in Huge Online Courses and Communities. Int. Rev. Res. Open Distrib. Learn. 2017, 18, 225-246. [CrossRef]

13. Ho, M.H.-C.; Liu, J.S.; Lu, L.Y.Y. Recent Themes in Social Networking Service Research. PLoS ONE 2017, 12, e0170293. [CrossRef]

14. Wood, J.; Kim, W.; Khan, G.F. Work engagement in organizations: a social network analysis of the domain. Scientometrics 2016, 109, 317-336. [CrossRef]

15. Lytras, M.D. The Semantic Electronic Government: knowledge management for citizen relationship and new assessment scenarios. Electron. Gov. Int. J. 2005, 3, 5-17. [CrossRef]

16. Barth, J.; Fietkiewicz, K.; Gremm, J.; Hartmann, S.; Ilhan, A.; Mainka, A.; Meschede, C.; Stock, W. Informational Urbanism. A Conceptual Framework of Smart Cities. In Proceedings of the 50th Hawaii International Conference on System Sciences (2017), Hilton Waikoloa Village, HI, USA, 4-7 January 2017. [CrossRef] 
17. Pérez-Delhoyo, R.; Mora, H.; Paredes, J.F. Using social network data to improve planning and design of smart cities. Urban Growth Circ. Econ. 2018, 179, 171-178. [CrossRef]

18. Lim, C.; Kim, K.-J.; Maglio, P.P. Smart cities with big data: Reference models, challenges, and considerations. Cities 2018, 82, 86-99. [CrossRef]

19. Batty, M. Big data, smart cities and city planning. Dialog. Hum. Geogr. 2013, 3, 274-279. [CrossRef] [PubMed]

20. Osman, A.M.S. A novel big data analytics framework for smart cities. Future Gener. Comput. Syst. 2019, 91, 620-633. [CrossRef]

21. Scuotto, V.; Ferraris, A.; Bresciani, S. Internet of Things. Bus. Process Manag. J. 2016, 22, 357-367. [CrossRef]

22. Bresciani, S.; Ferraris, A.; Del Giudice, M. The management of organizational ambidexterity through alliances in a new context of analysis: Internet of Things (IoT) smart city projects. Technol. Forecast. Soc. Chang. 2018, 136, 331-338. [CrossRef]

23. Rathore, M.M.; Ahmad, A.; Paul, A.; Rho, S.; Rho, S. Urban planning and building smart cities based on the Internet of Things using Big Data analytics. Comput. Netw. 2016, 101, 63-80. [CrossRef]

24. Babar, M.; Arif, F. Smart urban planning using Big Data analytics to contend with the interoperability in Internet of Things. Future Gener. Comput. Syst. 2017, 77, 65-76. [CrossRef]

25. Hatala, J.-P. Social Network Analysis in Human Resource Development: A New Methodology. Hum. Resour. Dev. Rev. 2006, 5, 45-71. [CrossRef]

26. Souri, A.; Nourozi, M.; Rahmani, A.M.; Navimipour, N.J. A model checking approach for user relationship management in the social network. Kybernetes 2018. [CrossRef]

27. Wasserman, S.; Faust, K. Social Network Analysis; Wasserman, S., Ed.; Cambridge University Press: Cambridge, UK, 1994; ISBN 9780511815478. [CrossRef]

28. Bossche, P.V.D.; Segers, M. Transfer of training: Adding insight through social network analysis. Educ. Res. Rev. 2013, 8, 37-47. [CrossRef]

29. Leon, R.-D.; Rodríguez-Rodríguez, R.; Gómez-Gasquet, P.; Mula, J. Social network analysis: A tool for evaluating and predicting future knowledge flows from an insurance organization. Technol. Forecast. Soc. Chang. 2017, 114, 103-118. [CrossRef]

30. Monaghan, S.; Lavelle, J.; Gunnigle, P. Mapping networks: Exploring the utility of social network analysis in management research and practice. J. Bus. Res. 2017, 76, 136-144. [CrossRef]

31. Shen, G.C.-C.; Chiou, J.-S.; Hsiao, C.-H.; Wang, C.-H.; Li, H.-N. Effective marketing communication via social networking site: The moderating role of the social tie. J. Bus. Res. 2016, 69, 2265-2270. [CrossRef]

32. Kim, J.; Hastak, M. Social network analysis: Characteristics of online social networks after a disaster. Int. J. Inf. Manag. 2018, 38, 86-96. [CrossRef]

33. Paul, P.V.; Monica, K.; Trishanka, M. A survey on big data analytics using social media data. In Proceedings of the 2017 Innovations in Power and Advanced Computing Technologies (i-PACT), Vellore, India, 21-22 April 2017. [CrossRef]

34. Romanillos, G.; Austwick, M.Z.; Ettema, D.; De Kruijf, J. Big Data and Cycling. Transp. Rev. 2016, 36, 114-133. [CrossRef]

35. Zhuhadar, L.; Yang, R.; Lytras, M.D. The impact of Social Multimedia Systems on cyberlearners. Comput. Hum. Behav. 2013, 29, 378-385. [CrossRef]

36. Stieglitz, S.; Mirbabaie, M.; Ross, B.; Neuberger, C. Social media analytics-Challenges in topic discovery, data collection, and data preparation. Int. J. Inf. Manag. 2018, 39, 156-168. [CrossRef]

37. Immonen, A.; Pääkkönen, P.; Ovaska, E. Evaluating the Quality of Social Media Data in Big Data Architecture. IEEE Access 2015, 3, 2028-2043. [CrossRef]

38. Liu, S.M.; Yuan, Q. The Evolution of Information and Communication Technology in Public Administration. Public Admin. Dev. 2015, 35, 140-151. [CrossRef]

39. Anthopoulos, L.; Fitsilis, P. Social networks in smart cities: Comparing evaluation models. In Proceedings of the 2015 IEEE First International Smart Cities Conference (ISC2), Guadalajara, Mexico, 25-28 October 2015; pp. 1-6. [CrossRef]

40. Giatsoglou, M.; Chatzakou, D.; Gkatziaki, V.; Vakali, A.; Anthopoulos, L. CityPulse: A Platform Prototype for Smart City Social Data Mining. J. Knowl. Econ. 2016, 7, 344-372. [CrossRef]

41. Lorimer, P.A.; Diec, V.M.-F.; Kantarci, B. COVERS-UP: Collaborative Verification of Smart User Profiles for social sustainability of smart cities. Sustain. Cities Soc. 2018, 38, 348-358. [CrossRef] 
42. Shelton, T.; Poorthuis, A.; Zook, M. Social media and the city: Rethinking urban socio-spatial inequality using user-generated geographic information. Landsc. Urban Plan. 2015, 142, 198-211. [CrossRef]

43. Ilieva, R.T.; McPhearson, T. Social-media data for urban sustainability. Nat. Sustain. 2018, 1, 553. [CrossRef]

44. Hamstead, Z.A.; Fisher, D.; Ilieva, R.T.; Wood, S.A.; McPhearson, T.; Kremer, P. Geolocated social media as a rapid indicator of park visitation and equitable park access. Comput. Environ. Urban Syst. 2018, 72, 38-50. [CrossRef]

45. Alvarez, L.; Borsi, K.; Rodrigues, L. The role of social network analysis on participation and placemaking. Sustain. Cities Soc. 2017, 28, 118-126. [CrossRef]

46. Martí, P.; Serrano-Estrada, L.; Nolasco-Cirugeda, A. Using locative social media and urban cartographies to identify and locate successful urban plazas. Cities 2017, 64, 66-78. [CrossRef]

47. Peng, X.; Huang, Z. A Novel Popular Tourist Attraction Discovering Approach Based on Geo-Tagged Social Media Big Data. Int. J. Geoinf. 2017, 6, 216. [CrossRef]

48. Encalada, L.; Boavida-Portugal, I.; Ferreira, C.C.; Rocha, J. Identifying Tourist Places of Interest Based on Digital Imprints: Towards a Sustainable Smart City. Sustainability 2017, 9, 2317. [CrossRef]

49. Mislove, A.; Koppula, H.S.; Gummadi, K.P.; Druschel, P.; Bhattacharjee, B. Growth of the flickr social network. In Proceedings of the First Workshop on Emerging Technologies for Software-Defined and Reconfigurable Hardware-Accelerated Cloud Datacenters-ETCD'17 2008, Seattle, WA, USA, 18 August 2018; p. 25. [CrossRef]

50. Liu, B.; Yuan, Q.; Cong, G.; Xu, D. Where your photo is taken: Geolocation prediction for social images. J Assoc. Inf. Sci. Technol. 2014, 65, 1232-1243. [CrossRef]

51. Yin, J.; Soliman, A.; Yin, D.; Wang, S. Depicting urban boundaries from a mobility network of spatial interactions: a case study of Great Britain with geo-located Twitter data. Int. J. Geogr. Inf. Sci. 2017, 71, 1293-1313. [CrossRef]

52. Tse, R.; Zhang, L.F.; Lei, P.; Pau, G. Social Network Based Crowd Sensing for Intelligent Transportation and Climate Applications. Mob. Netw. Appl. 2018, 23, 177-183. [CrossRef]

53. Bacco, M.; Delmastro, F.; Ferro, E.; Gotta, A. Environmental Monitoring for Smart Cities. IEEE Sens. J. 2017, 17, 7767-7774. [CrossRef]

54. Aguilera, M. Rhythms of the Collective Brain: Metastable Synchronization and Cross-Scale Interactions in Connected Multitudes. Complexity 2018, 2018, 4212509. [CrossRef]

55. Xu, P.; Wu, Y.; Wei, E.; Peng, T.-Q.; Liu, S.; Zhu, J.J.H.; Qu, H. Visual Analysis of Topic Competition on Social Media. IEEE Trans. Vis. Comput. Graph. 2013, 19, 2012-2021. [CrossRef] [PubMed]

56. Resch, B.; Summa, A.; Zeile, P.; Strube, M. Citizen-Centric Urban Planning through Extracting Emotion Information from Twitter in an Interdisciplinary Space-Time-Linguistics Algorithm. Urban Plann. 2016, 1, 114. [CrossRef]

57. Resch, B.; Summa, A.; Sagl, G.; Zeile, P.; Exner, J.P. Urban Emotions: Geo-Semantic Emotion Ex-Traction from Technical Sensors, Human Sensors and Crowdsourced Data, Progress in Location-Based Services; Springer: Cham, Switzerland, 2014; pp. 199-212.

58. Li, Z.; Hong, H.; Zhu, S.; Li, Y.; El Saddik, A. City digital pulse: a cloud based heterogeneous data analysis platform. Multimed. Tools Appl. 2017, 76, 10893-10916. [CrossRef]

59. Zeng, W.; Fu, C.-W.; Arisona, S.M.; Schubiger, S.; Burkhard, R.; Ma, K.-L. Visualizing the Relationship Between Human Mobility and Points of Interest. IEEE Trans. Intell. Transport. Syst. 2017, 18, 2271-2284. [CrossRef]

60. Wu, F.; Zhu, M.; Wang, Q.; Zhao, X.; Chen, W.; Maciejewski, R. Spatial-temporal visualization of city-wide crowd movement. J. Vis. 2017, 20, 183-194. [CrossRef]

61. Bunn, H. Data-Driven Bicycle and Pedestrian Planning. 10 March 2017. Available online: https: / / medium.com/strava-metro/data-driven-bicycle-and-pedestrian-planning-40d209284481 (accessed on 29 October 2018).

62. Selala, M.K.; Musakwa, W. The potential of strava data to contribute in non-motorised transport (nmt) planning in johannesburg. Int. Arch. Photogramm. Remote Sens. Spat. Inf. Sci. 2016, 587-594. [CrossRef]

63. MacMichael, S. Strava Moves into 'Big Data'-London \& Glasgow Already Signed up to Find out Where Cyclists Ride. Road.cc, 2014. Available online: https:/ / road.cc/content/news/118098-strava-moves-bigdata-london-glasgow-already-signed-find-out-where-cyclists-ride (accessed on 27 October 2018). 
64. Zeile, P.; Resch, B.; Exner, J.-P.; Sagl, G. Urban Emotions: Benefits and Risks in Using Human Sensory Assessment for the Extraction of Contextual Emotion Information in Urban Planning. In Planning Support Systems and Smart Cities; Springer: Cham, Switzerland, 2015; pp. 209-225. [CrossRef]

65. De Oliveira, À.D. The Human Smart Cities Manifesto: A Global Perspective; Springer Nature: Cham, Switzerland, 2016; pp. 197-202.

66. Marsal-Llacuna, M.-L.; Leung, Y.T.; Ren, G.-J. Smarter urban planning: match land use with citizen needs and financial constraints. In Proceedings of the International Conference on Computational Science and Its Applications, Santander, Spain, 20-23 June 2011; pp. 93-108. [CrossRef]

67. Goldsmith, S.; Crawford, S. The Responsive City: Engaging Communities through Data-Smart Governance; John Wiley \& Sons: San Francisco, CA, USA, 2014; ISBN 978-1-118-91090-0.

68. Oliveira, A.; Campolargo, M. From Smart Cities to Human Smart Cities. In Proceedings of the 201548 th Hawaii International Conference on System Sciences, Kauai, HI, USA, 5-8 January 2015; pp. 2336-2344. [CrossRef]

69. Jansen, B. Strava Fitness Tracking Map Reveals Military Bases, Movements in War Zones. USA Today, 29 January 2018. Available online: https:/ / eu.usatoday.com/story/news/world/2018/01/29/strava-warzones/1073975001/ (accessed on 27 October 2018).

70. Strava. Available online: https://www.strava.com/heatmap (accessed on 27 October 2018).

71. Berezan, O.; Krishen, A.S.; Agarwal, S.; Kachroo, P. The pursuit of virtual happiness: Exploring the social media experience across generations. J. Bus. Res. 2018, 89, 455-461. [CrossRef]

72. Núñez, J. Alicante Cierra el año 2017 con una Cifra Récord de Turistas. Available online: https: / / alicantepress. com/art/35852/alicante-cierra-el-ano-2017-con-una-cifra-record-de-turistas (accessed on 30 October 2018). (In Spanish)

73. Ferraris, A.; Erhardt, N.; Bresciani, S. Ambidextrous work in smart city project alliances: unpacking the role of human resource management systems. Int. J. Hum. Resour. Manag. 2017, 1-22. [CrossRef]

74. Yin, Y.K. Case Study Research: Design and Methods, 5th ed.; Sage Publications: Newbury Park, CA, USA, 2013; ISBN 9781452242569.

75. Flyvbjerg, B. Five Misunderstandings about Case-Study Research. Qual. Inq. 2006, 12, 219-245. [CrossRef]

76. Pérez-Delhoyo, R.; Andújar-Montoya, M.D.; Mora, H.; Gilart-Iglesias, V. Unexpected consequences in the operation of urban environments. Kybernetes 2018. [CrossRef]

77. Gadais, T.; Boulanger, M.; Trudeau, F.; Rivard, M.-C. Environments favorable to healthy lifestyles: A systematic review of initiatives in Canada. J. Sport Health Sci. 2018, 7, 7-18. [CrossRef] [PubMed]

78. Marans, R.W. Quality of urban life \& environmental sustainability studies: Future linkage opportunities. Habitat Int. 2015, 45 Pt 1, 47-52. [CrossRef]

79. Mecredy, G.; Pickett, W.; Janssen, I. Street Connectivity is Negatively Associated with Physical Activity in Canadian Youth. Int. J. Environ. Res. Public Health 2011, 8, 3333-3350. [CrossRef]

80. Netto, V.M.; Meirelles, J.; Ribeiro, F.L. Social Interaction and the City: The Effect of Space on the Reduction of Entropy. Complexity 2017, 2017, 6182503. [CrossRef]

(C) 2018 by the authors. Licensee MDPI, Basel, Switzerland. This article is an open access article distributed under the terms and conditions of the Creative Commons Attribution (CC BY) license (http:/ / creativecommons.org/licenses/by/4.0/). 